\title{
Verkehrsverbund: The Evolution and Spread of Fully-Integrated Regional Public Transport in Germany, Austria, and Switzerland
}

\author{
By Ralph Buehler, John Pucher, and Oliver Dümmler
}

\begin{abstract}
Throughout the world, urban areas have been rapidly expanding, exacerbating the problem of many public transport (PT) operators providing service over different governmental jurisdictions. Over the past five decades, Germany, Austria, and Switzerland have successfully implemented regional PT associations (called Verkehrsverbund or VV), which integrate services, fares, and ticketing while coordinating public transport planning, marketing, and customer information throughout metropolitan areas, and in some cases, entire states. A key difference between VVs and other forms of regional PT coordination is the collaboration and mutual consultation of government jurisdictions and PT providers in all decision-making.

This article examines the origins of VVs, their spread to 13 German, Austrian, and Swiss metropolitan areas from 1967 to 1990, and their subsequent spread to 58 additional metropolitan areas from 1991 to 2017, now serving 85\% of Germany's and 100\% of Austria's population. The VV model has spread quickly because it is adaptable to the different degrees and types of integration needed in different situations.

Most of the article focuses on six case studies of the largest VVs: Hamburg (opened in 1967), Munich (1971), Rhine-Ruhr (1980), Vienna (1984), Zurich (1990), and Berlin-Brandenburg (1999). Since 1990, all six of those VVs have increased the quality and quantity of service, attracted more passengers, and reduced the percentage of costs covered by subsidies. By improving PT throughout metropolitan areas, WVs provide an attractive alternative to the private car, helping to explain why the car mode share of trips has fallen since 1990 in all of the case studies.
\end{abstract}

Keywords: public transport, regional coordination, multimodal integration, public transport association, Europe 


\title{
Verkehrsverbund: The Evolution and Spread of Fully-Integrated Regional Public Transport in Germany, Austria, and Switzerland
}

\author{
By Ralph Buehler, John Pucher, and Oliver Dümmler
}

\section{Introduction}

Over the past five decades, Germany, Austria, and Switzerland have successfully implemented regional public transport (PT) associations, called Verkehrsverbünde (plural), which coordinate PT planning, services, fare structures, ticketing, marketing, and customer information throughout entire metropolitan areas, and in some cases, entire states (Buehler et al., 2015; Homburger and Vuchic, 1972; Pucher and Kurth, 1996; Topp, 1989; VDV, 2009). Verkehrsverbünde (VVs) facilitate the collaboration of PT operators with state, regional, district, and city governmental jurisdictions throughout the service area. Unlike regional PT organizations in most other countries, VVs include both PT operators and government representatives in the process of making policy decisions about services and fares (Eno Foundation, 2014; Koch and Newmark, 2017; VDV, 2009). Moreover, the overall degree of integration provided by a Verkehrsverbund (singular) is greater, offering one unified route network (all modes, all lines), fully coordinated schedules, and one fare structure and ticketing system. Although there is variation among VVs in the details of their organizational structure and decision-making process, all VVs offer their customers fully integrated regional PT (Dümmler, 2015; Pucher and Kurth, 1996).

The enhanced quality of service VVs provide is crucial for PT to compete effectively with the private car in European and North American metropolitan areas, which are increasingly spreading out into formerly rural areas (Buehler and Pucher, 2012; Eno Foundation, 2014;

Redman et al., 2013). Indeed, throughout the world, urban areas have been rapidly expanding to cover larger areas, exacerbating the problem of a multitude of different PT operators providing 
service over many different governmental jurisdictions (Dimitrou and Gakenheimer, 2011;

Dojani and Stead, 2017; Mees, 2010). It is the success of VVs in dealing with precisely this problem that explains why the VV form of PT organization has spread from only one city (Hamburg) in 1967 to 61 VVs in Germany in 2017 (serving 85\% of its population) and 8 VVs in Austria (serving 100\% of its population) (Dümmler, 2015; Koch and Newmark, 2017; VDV, 2009). Moreover, the largest Swiss city, Zurich, and its surrounding county are also served by a VV (Vollmer and Schiesser, 2009).

Past research has highlighted the crucial importance of coordination for transport in general, both for passenger and freight transport. For example, Banister and Givoni (2010), Hull (2005), Preston (2012), Rivasplata et al. (2012), and Stead (2008) examine the increasing need for regional and intermodal coordination within transport and between transport and many related government policies such as land use. As urban areas have grown both in population and area, they have also become increasingly fragmented, with many different government jurisdictions, transport operators, and types of land use. Coordination has also become more difficult due to trends toward privatization of the transport sector and decentralization of government functions to lower levels, resulting in more public and private decisionmakers as well as more competition (Hansson, 2013; Hrelja et al., 2017; Hrelja et al., 2016; Sørensen and Longva, 2011). Some researchers have characterized the lack of coordination in transport as a market failure requiring explicit government intervention to provide the necessary integration (O’Sullivan and Patel, 2005).

As confirmed by many researchers, PT is an essential component of a sustainable urban transport system (Banister, 2005; Banister, 2011; Cervero, 1998; Newman and Kenworthy, 1999; Suzuki et al., 2013; Vuchic, 1999). These studies show that the increasingly decentralized, 
sprawled development in metropolitan areas, especially since the 1950s, has promoted car use while making PT less attractive. In general, PT is most effective-and costs least per passenger km-with high-volume traffic corridors focused on a dense urban core (White, 2016). The dispersed trip patterns generated by sprawl put PT at a competitive disadvantage, which, however, can be minimized by fully coordinating PT modes and routes with each other and with other forms of transport and by integrating PT services over entire metropolitan regions (Mees, 2010; Petersen, 2016).

This article documents the success of VVs in fully integrating PT across entire metropolitan areas. The key results have been large increases in PT usage and declines in the car share of trips in core cities of many metropolitan areas in Germany, Austria, and Switzerland (Buehler et al., 2017b). Moreover, car mode shares for the countries as a whole have fallen or stabilized over the past few decades (BFS, 2017; BMVIT, 2017; MOP, 2017).

Although the article provides some information on aggregate, nationwide trends, the analysis focuses on the four largest VVs in Germany (Rhine-Ruhr, Berlin-Brandenburg, Hamburg, and Munich), the largest VV in Austria (Vienna), and the largest VV in Switzerland (Zurich). Not only are these the largest VVs in the three countries, but they also include the oldest, thus enabling an examination of trends over a longer period of time than would be possible with more recently founded VVs. This article has several research objectives:

(1) To review the scientific literature on the topic of VVs in the broader context of the growing need for regional PT coordination.

(2) To document the increasing number and geographic spread of VVs from 1967 to 2017.

(3) To examine the motivations and process for founding VVs. 
(4) To explain changes over time and across VVs in organizational structure and how they function.

(5) To analyze data from the six largest VVs to assess their performance in terms of raising passenger ridership while reducing or stabilizing levels of car use.

(6) To examine specific types of policies implemented by the six largest VVs to increase PT ridership.

(7) To consider the transferability of the VV organizational form to cities in other countries.

\section{Review of literature on public transport integration}

There have been several publications focusing on the specific topic of VVs. In one of the earliest studies, Homburger and Vuchic (1972) examined the first few years of the VV in Hamburg (founded in 1967) and on the basis of its initial success, suggested its innovative coordination of PT as a model for other metropolitan areas to follow. Dunn (1980) also examined Hamburg's VV and came to the same conclusion as Vuchic. Topp (1989) updated the two earlier studies by analyzing the impacts of VV coordination of PT on productivity, cost, subsidy needs, service quality, fares, and passenger trips in 6 of 11 German VVs that existed by the late 1980s. Similar to Vuchic and Dunn, Topp finds the specific kind of regional PT coordination provided by VVs essential to improving PT services and making them competitive with the private car. His main concern was the large increase in operating deficits and subsidy needs in most VVs.

Pucher and Kurth (1996) further updated the preceding studies, examining the spread of VVs to 14 German, Austrian, and Swiss metropolitan areas by 1993. Their study found that VVs produced large increases in PT passenger trips, both due to service expansion and improvement and much more attractive fare structures. Similar to Topp, the main problem they identified was 
the large increase in subsidy requirements to offset the declining portion of operating costs covered by passenger fares. Fitzroy and Smith (1998) as well as Buehler and Pucher (2011b) emphasize the crucial role of Freiburg's VV in providing fully-integrated, multi-modal, regionwide ticketing, which also facilitated deep discounts for regular riders using monthly, semester, and annual PT tickets. Cervero (1998) found that VV coordination was key to the success of the PT systems in Munich and Zurich, especially in terms of providing high-quality service at attractive fares, increasing passenger trips, and competing effectively with the private car.

The German PT Association (VDV, 2009) published an edited book about VVs with 20 chapters, providing historical overviews of VV development and expansion, perspectives from VVs in various German cities, examination of specific aspects of VV functions (such as marketing and ticketing), and brief summaries of the Swiss and Austrian experience with VVs. The main conclusion of the book is that VVs have proven to be an extraordinarily successful way to fully integrate PT services, and are the most important reason for increased usage of PT and its improved competitiveness with the private car in Germany. Another indicator of the success of VVs documented in the book is the sharp rise in the number of VVs and their geographic spread to cover most of Germany’s population.

One of the important achievements of VVs has been the extension of PT services to suburban and rural areas, and their integration with urban routes to form truly regional networks of coordinated PT service. Mees (2010) examines the Zurich VV in his book on PT for suburban area and finds the VV model of PT integration ideal for the difficult but important task of improving PT services to the rapidly growing suburban development around cities throughout in the world. Similarly, Petersen (2016) finds that coordination of PT services-especially 
integrated timetables—in rural areas of Switzerland has been crucial to providing a high-quality PT service to those areas and connecting them to the country's cities. Dümmler (2015), Mees (2010), Petersen (2016), and Vuchic (1999, 2005) suggest that VVs provide an important social service by enhancing the mobility of carless households, as well as seniors and children, in rural areas. The larger PT subsidies (per passenger $\mathrm{km}$ ) generally required in suburban and rural areas might thus be justified as a social service in terms of the enhanced accessibility provided for otherwise mobility-disadvantaged groups. Moreover, the inclusion of such lower-density areas in the VV is viewed by these authors as necessary to provide a truly regionwide PT network.

Although larger subsidies are usually necessary to expand the VV service area to include suburban and rural areas, VVs can help reduce certain costs. For example, Buehler and Pucher (2011a) find that VVs have enabled German PT operators to eliminate redundant services and share certain costs such as administration, finance, ticketing, marketing and vehicle maintenance. Moreover, due to synergistic network effects, VVs facilitate the realization of economies of scope, thus increasing the potential benefits to users of any given link in the system (Bruun, 2007; Vuchic, 2005; White, 2016).

Koch and Newmark (2017) document the overall increase in the number of VVs from one in 1967 to 59 in 2005. They examine the impact of changing EU and national regulations encouraging more competition and privatization of PT. The authors conclude that the VV form of fully-integrated regional PT is the ideal framework to accommodate the mandated competition and privatization within the PT sector while maintaining a truly coordinated, unified PT network that ensures the systemic benefits of an integrated regional system.

There are, of course, different kinds and degrees of PT cooperation, coordination, and integration. The International Association of Public Transport (UITP, 2014) provides a detailed 
listing of PT organization, regulation, governance, and types of PT coordination, both in urban and rural areas, for $23 \mathrm{EU}$ countries. In virtually every EU country, there is some sort of coordination and cooperation among PT operators within metropolitan areas, and often within rural areas as well. The VV is unique as an organizational form, however, because of the full integration of services and fares among the many PT operators and governmental entities found in German, Austrian, and Swiss cities. The German PT Association (VDV, 2009) finds the VV form special, not only because it offers "one timetable, one fare, and one ticket,” but also because it relies on mutual cooperation and feedback among and between PT operators and government representatives, with decisions made jointly by consensus. As VDV emphasizes, VVs are associations and not public authorities, the usual form of PT coordination in many other countries.

Several recent studies examine regional PT coordination from the perspective of governance, institutional arrangements, and 'new public management,' which seeks to increase public sector efficiency based on the consumer-oriented and cost-conscious approach of the private sector. Many of these studies focus on the increasingly important relationship between governments and private companies due to trends in privatization and public tendering, while others look at issues of regional governance among multiple government stakeholders.

Van de Velde (1999, 2001) surveyed the different kinds of PT organization in the 1990s in 11 Western European countries (Belgium, Denmark, France, Germany, Great Britain, Ireland, Italy, Netherlands, Portugal, Spain, and Sweden). In general, he categorizes PT organizations as market-oriented (mostly private), authority-oriented (publicly owned and managed), or some combination of the two. Although Van de Velde notes the important impact of increased liberalization and deregulation (including competitive tendering) on PT in the 1990s, he 
emphasizes that public ownership and management continued to dominate PT provision in most of Europe. In his updated analysis of the same topic, Van de Velde (2014) finds that private provision of PT services has increased greatly in Europe since the 1990s due to further EU and national legislation promoting privatization and competition. The major drawback Van de Velde identifies for the market-based model of PT provision is the failure to integrate fare structures and ticketing, one of the major strengths of VVs highlighted in this article.

Recent studies, mainly from Scandinavian countries, analyze collaboration of different stakeholders for successful regional PT coordination. As noted by Hansson (2013), the organizations involved in Swedish PT are municipalities, county councils, regional transport planning agencies, and county PT authorities. Hansson found that the county PT authority serves a crucial moderating role in the coordination of PT service planning and provision, as well as fare integration, confirming the need for a special regional PT organization to ensure regional coordination. Another case study from Sweden finds that informal relationships among stakeholders can improve collaboration, but that formal coordinating bodies are required because informal relationships cannot be legally enforced (Hrelja et al., 2017). Sørensen and Longva (2011) note that the trend toward new public management in Denmark, Sweden, and the UK has increased the need for explicit coordination of regional PT services among the rising number of PT operators and governmental representatives resulting from privatization, competition, and decentralization of government decision-making. Thus, all three studies provide evidence on the increasingly important need for regional PT coordination, such as that facilitated by the VVs examined in this article. 


\section{Data sources and case study selection}

There are no comprehensive datasets with comparable statistics over time for VVs in Germany, Austria, and Switzerland. Thus, it was necessary to gather data from each individual VV to be studied. Moreover, some VVs—especially in smaller towns and rural areas—were not able or willing to make their limited data publicly available. The difficulty of obtaining VV data forced us to focus on only a few detailed case studies. Thus, we chose the six largest and oldest VVs in the three countries (official acronyms and opening years shown): Hamburg (HVV) in 1967, Munich (MVV) in 1971, Rhine-Ruhr (VRR) in 1980, Vienna (VOR) in 1984, Zurich (ZVV) in 1990, and Berlin-Brandenburg (VBB) in 1999. Restricting our analysis to these VVs facilitated data collection as well as comparability.

All six case study VVs serve major metropolitan areas with many PT operators and many government jurisdictions at various levels (national, state, regional, local). The VVs have integrated a wide range of PT services: urban, suburban and regional bus; trams (light rail); urban metro; and suburban and regional rail. Moreover, five of them provide about 25 years of time-trend data, with Berlin providing 15 years. In comparison, some of the newer VVs are only a small fraction of the size of our case study VVs, have data for only a few years, and only offer bus services. Even if time-trend statistics for them were available, their much smaller size would make comparisons questionable. Yet another reason for the choice of our six VVs is that they all have the same type of internal organization, as noted in section 6 , and thus are comparable with each other in that respect as well.

Our case study analysis relied on information from various types of documents: peerreviewed academic publications; studies conducted by consulting firms, government agencies, and national PT associations; VV and PT firm annual reports, statistical publications, public 
presentations, and their official websites. Each of these documents is cited specifically in the text, tables, and figures, and listed in the references at the end of the paper. We supplemented that information from documents with extensive e-mail exchanges, telephone conversations, and in-person interviews with representatives of each of the six case study VVs and the German PT Association (VDV). All twelve contact persons at the VVs and VDV are listed in detail (and identified by city and organization) in the Acknowledgements section at the end of this paper. These contacts supplied additional information not publicly available, helped fill in data gaps, and clarified various questions we had about the data. They also shared qualitative background information not available in printed documents. These were not formal, structured interviews but rather specific inquiries to obtain supplemental information, which varied from case to case, depending on what additional information we needed.

\section{Expansion of Verkehrsverbünde, 1967-2017}

Figure 1 shows the increasing number of VVs in Germany, Austria, and Switzerland between 1967 and 2017—based on the year when new VVs started operations. There are three distinct phases of the creation of VVs: 1967-1990, 1991-2000, and 2001-2017. All 13 VV's founded between 1967 and 1990 were in large metropolitan areas with multiple PT modes and providers. As explained in detail in section 6 of this article, PT operators had the most powerful role on the VV governing boards of the 11 German VVs founded during this initial phase (Dümmler, 2015). Local and state governments provided funding and served in an advisory role. In Vienna and Zurich, however, local, state, and federal governments had the leading role on VV boards. From 1967 to 1990, most PT operators and government officials in all three countries concluded that VVs would only be viable in large urbanized areas with many different operators and with trips traversing jurisdictional boundaries (Knieps, 2004). 


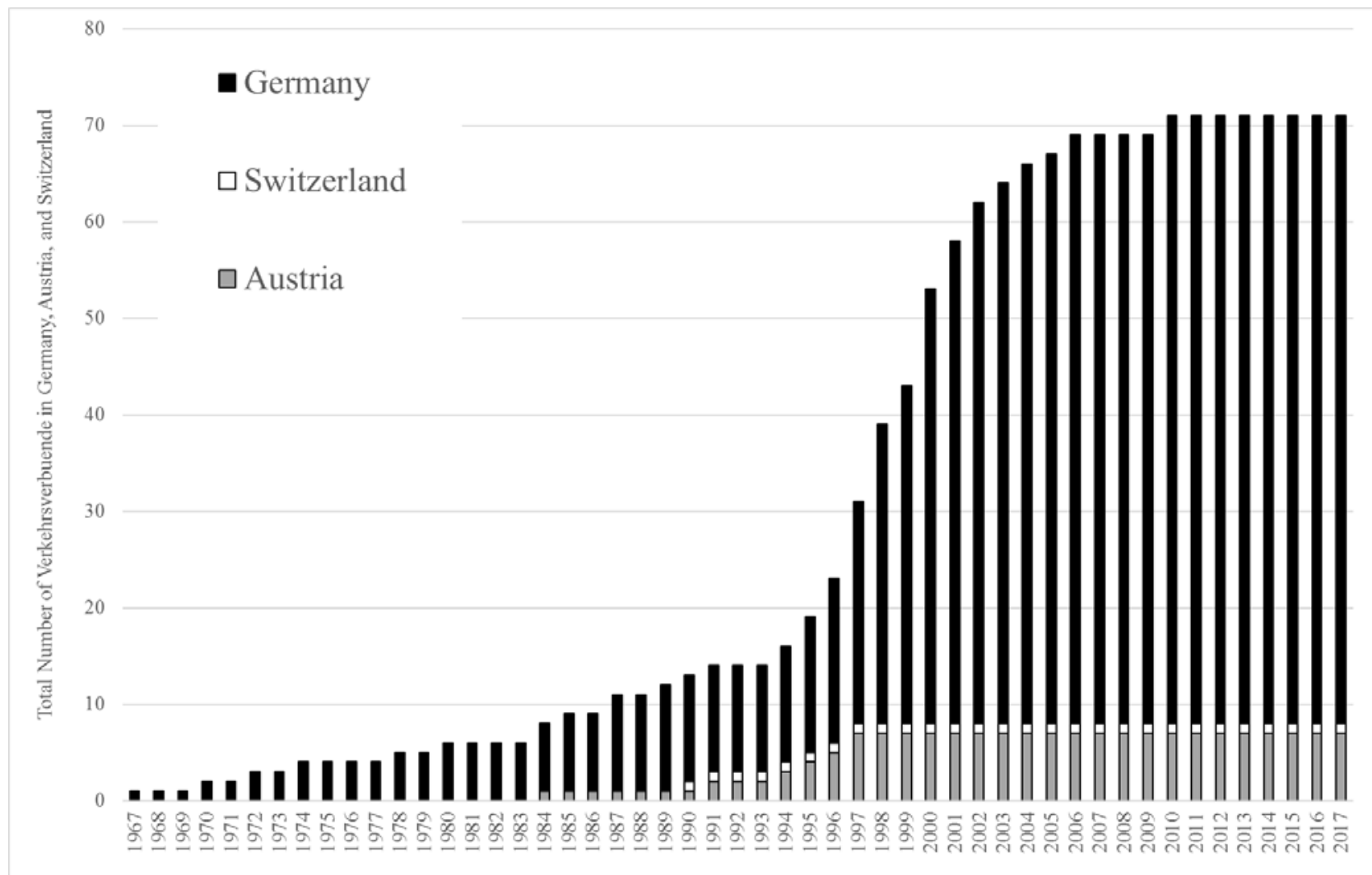

Figure 1. Expansion of Verkehrsverbünde in Germany, Austria, and Switzerland, 19672017.

Sources: (Dümmler, 2015; Koch and Newmark, 2017; VDV, 2009)

Note: The graph only includes VVs currently in operation, thus excluding VVs that no longer exist because of their amalgamation into larger VVs.

While it took 23 years for VVs to spread from Hamburg (founded in 1967) to 13 other regions, the number of VVs more than tripled from 13 to 50 between 1991 and 2000 (Figure 1). With some exceptions, like Berlin or Bremen, most of the new VVs founded between 1991 and 2000 were outside of large urbanized areas. Several were in regions or states surrounding midsized cities with 200,000-300,000 inhabitants, such as Freiburg, Karlsruhe, Münster, and Graz. Many were in areas surrounding small urban centers with fewer than 100,000 inhabitants (Dümmler, 2015; VDV, 2009).

Following the boom period between 1991 and 2000, the spread of VVs slowed down, with 17 new VVs founded between 2001 and 2006, and then only two new VVs between 2007 
and 2017. One reason for this slow-down is that virtually all large and mid-sized urban areas in Germany and Austria were already part of a VV. Since 2001, new VVs have been in small cities, towns, and rural areas. By 2009, $85 \%$ of the German population and $100 \%$ of the Austrian population lived in an area served by a VV (Dümmler, 2015; Novy, 2009). It is doubtful that VVs will spread to the remaining rural areas of Germany because public transport demand and supply there are very low.

Figure 2 shows the spatial expansion of VVs over the three time periods: 1967-1990 (brown), 1991-2000 (orange), and 2001-2017 (yellow). As evident in the map, most of Germany and all of Austria were served by VVs by 2017. The six case study VVs are indicated on the map by their official acronyms, as explained in the footnote to the map. 


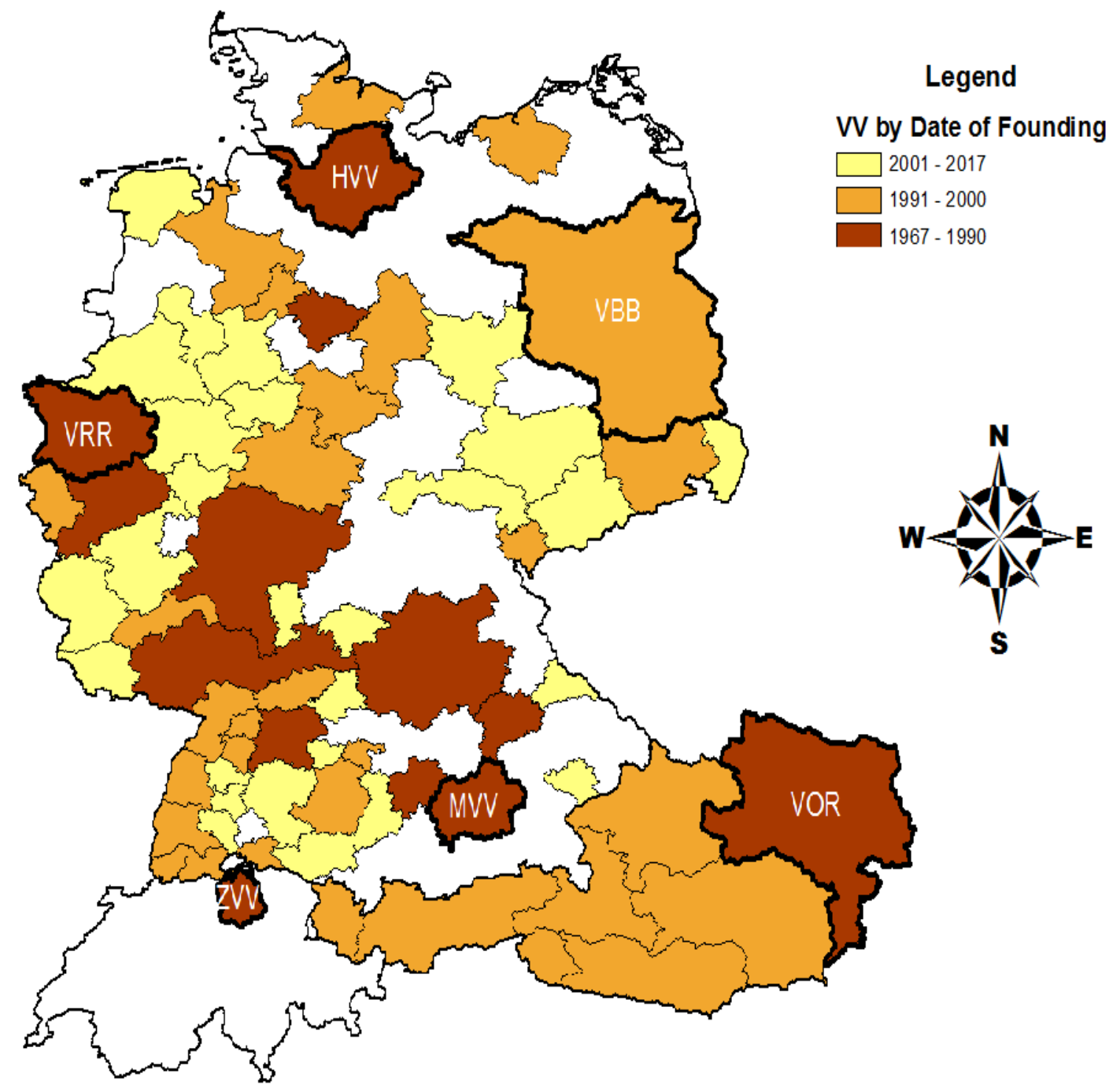

Figure 2. Expansion of Verkehrsverbünde in Germany, Austria, and Switzerland, 19672017. Source: (Dümmler, 2015; VDV, 2001-2017, 2009). Map created by Bryan Botello. Note: the six case study Verkehrsverbünde are designated on this map by their official acronyms: HVV (Hamburg), MVV (Munich), VBB (Berlin-Brandenburg), VOR (Vienna), VRR (Rhine-Ruhr), and ZVV (Zurich).

\section{Motivation and process of founding VVs}

There were many developments in the 1960s and 1970s that provided motivation for regional coordination of PT. Car ownership rates per 1,000 residents more than tripled from 1960 to 1980 in all three countries and for all six of the VV core cities (Buehler et al., 2017b; Eurostat, 2017), leading to worsening congestion, pollution, and parking shortages, as well as 
increasing traffic fatalities and injuries. At the same time, decentralization of urban areas made it increasingly difficult and expensive to provide PT service, especially in low-density, caroriented suburbs. As car use rose, PT usage fell—along with PT operating revenues—posing serious financial problems for PT firms and providing them with more incentive to cooperate with other PT firms and to seek financial assistance from local governments (Baron, 1995; Dunn, 1981; Pucher and Lefevre, 1996; TRB, 2001; Yago, 1984). Central cities viewed improved regional PT as key to reversing their decline as both residents and businesses moved increasingly to the suburbs. Thus, both PT firms and central city governments had strong incentives to support the formation of VVs.

For example, the main PT operator in Hamburg (owned by the city) took the initiative of reaching out to other PT operators and local governments in the region to explore ways to facilitate integration of their uncoordinated PT services and fares. The result was the first VV, starting operations in 1967. As part of the agreement, the City of Hamburg guaranteed regional rail and bus operators that it would provide financing to offset losses resulting from integrated operations (Homburger and Vuchic, 1972; Krause, 2009; VDV, 2009). Hamburg’s VV (HVV) served as a model for VVs in other metropolitan areas.

The extraordinary success of Hamburg's VV, and those that soon followed, was an important factor in encouraging the spread of VVs to other metropolitan areas. Moreover, as an increasing number of regions adopted the VV form of PT integration, some regions founded their own VVs to keep up with the trend and maintain their competitiveness relative to other regions. The motivations for founding the earliest VVs apply to all subsequent VVs as well: namely, dealing with the financial problems of PT and improving the overall quality of PT service to discourage car use (Dümmler, 2015; VDV, 2009). 
Many VVs were founded to help integrate large infrastructure projects into the regional PT system. The VVs in Munich, Vienna, and Zurich were established concurrent with the construction of their new U-Bahn and S-Bahn systems (Bruehweiler et al., 2015; MVV, 2012; Novy, 2009). The upgrading of regional rail and S-Bahn connections in the Rhine-Ruhr area were facilitated by the VV there (VRR, 2015).

In some cases, VVs were founded on the basis of federal initiatives. For example, the VV in Berlin was explicitly recommended by the German Reunification Treaty of 1990 as a means to integrate the disjoint PT systems in the former East and West Berlin as well as suburbs in the surrounding State of Brandenburg. As part of the reunification effort, the German federal government provided massive funding for infrastructure finance in Berlin (Franz, 2007). The Vienna VV (VOR) was founded in 1984 as a combined city, state, and federal effort, with all three government levels agreeing to share the costs of coordinating PT via the VV, and to offset the potential revenue losses of participating PT firms resulting from the unified fare structure (Novy, 2009; Rollinger and Amtmann, 2012). VOR’s success led the Austrian federal government to pass legislation in 1999 mandating VVs in all Austrian states and providing special federal funding to cover their administrative and planning costs (Novy, 2009). Similarly, the State of Bavaria and the German federal government (in preparation for the 1972 Olympics) financed most of the cost of the new U-Bahn and S-Bahn systems that became the backbone of the integrated PT network in the Munich VV (MVV, 2012). The state (Kanton Zurich) and Swiss federal government jointly financed the new Zurich S-Bahn—approved by a state-wide referendum in 1988 (Bruehweiler et al., 2015), which as in Munich was a key element in regional PT integration. 
In Germany, changes in transport legislation by the federal government stimulated the especially rapid expansion of VVs from about 1995 to 2005 (as shown in Figure 1) (Knieps, 2004; Koch and Newmark, 2017). Starting in 1995, and continuing through 2015, a series of new German federal and state laws—combined with new EU regulations—-have increasingly decentralized planning and funding for PT to state and local governments (Barth, 2013; Bormann et al., 2010; Dümmler, 2015). Each German state is now responsible for planning and funding regional rail transport. Moreover, federal and state laws require local governments to take the lead role in funding public transport, and to cooperate with other local jurisdictions to create regional public transport plans. All of these legislative developments over the past two decades have further encouraged the founding of VVs to facilitate regional coordination of PT services and funding. As noted in the following section, federal and state legislation has also led to organizational restructuring of VVs.

\section{Variation in types of VVs and their organizational structure}

In the introduction of this article, we defined VVs in general and only briefly noted the variation in types of VVs and differences in their organizational structure. The German PT Association (VDV, 2009) groups VVs into three general categories: UVs (Unternehmensverbünde), AVs (Auftraggeberverbünde), and MVs (Mischverbünde). As shown in Figure 3, all three types of VVs include cooperation among and between PT firms and government jurisdictions. In UVs, PT firms have the leading role in decisionmaking on the VV governing board, but government jurisdictions provide funding. Moreover, most large PT firms are owned by local jurisdictions, which thus have an impact indirectly on VV policies. In AVs, government jurisdictions have the leading role, but PT firms provide important input relating to operations. MVs are a mix of UVs and AVs, with PT firms and government jurisdictions having 
comparable influence. These three types are only approximate categories established by VDV to generalize differences in organization and decisionmaking within VVs (Dümmler, 2015).

\begin{tabular}{|c|c|c|}
\hline Unternehmensverbund (UV) & Mischverbund (MV) & Aufgabenträgerverbund (AV) \\
\hline Government Jurisdictions & Government Jurisdictions & Government Jurisdictions \\
\hline $\begin{array}{l}\text { Cooperation \& } \\
7 \quad \text { advice }\end{array}$ & $\begin{array}{c}\text { Shared influence } \\
\text { on governing } \\
\text { board }\end{array}$ & $\begin{array}{c}\text { Dominant } \\
\text { influence on } \\
\text { governing board }\end{array}$ \\
\hline $\begin{array}{l}\text { Verkehrsverbund Executive Body } \\
\text { (Board, Management, Planning) }\end{array}$ & $\begin{array}{l}\text { Verkehrsverbund Executive Body } \\
\text { (Board, Management, Planning) }\end{array}$ & $\begin{array}{l}\text { Verkehrsverbund Executive Body } \\
\text { (Board, Management, Planning) }\end{array}$ \\
\hline $\begin{array}{c}\text { Dominant } \\
\text { influence on } \\
\text { governing board }\end{array}$ & $\begin{array}{c}\text { Shared influence } \\
\text { on governing } \\
\text { board }\end{array}$ & $\begin{array}{l}\text { Cooperation \& } \\
\text { advice }\end{array}$ \\
\hline PT Operators (Firms) & PT Operators (Firms) & PT Operators (Firms) \\
\hline
\end{tabular}

Figure 3. Organizational Structures of Verkehrsverbünde

Source: Based on information in Dümmler, 2015 and VDV, 2009

The organizational structure of VVs has changed considerably over time and varies among VVs. All VVs founded prior to 1990 were UVs, with PT operators dominating their governing boards, relegating state and local governments to an advisory role, as in the first VV in Hamburg. As noted in Section 5, new German federal and state laws in the mid-1990s mandated a more important role for state and local governments in urban PT planning and funding (Bormann et al., 2010; Koch and Newmark, 2017). In addition, local and state governments wanted more control on VV governing boards because of their increasing contributions to funding VVs. As shown by Pucher and Kurth (1996) and Topp (1989), government subsidies required by VVs increased sharply during the 1980s and early 1990s, mainly due to increased service and deeply discounted season tickets (Dümmler, 2015; Knieps, 2004; VDV, 2009). Thus, most existing UVs and some MVs became AVs. This was especially the case in large metropolitan areas with extensive PT systems and large government financing. 
All large VVs in Germany (except Nuremberg) are currently AVs (Dümmler, 2015). All VVs in Austria and Switzerland are also AVs, with state and local governments taking the lead role because government jurisdictions have been more important in the founding, decision making, and financing of VVs there, including the two examined in this article (Vienna and Zurich) (Novy, 2009; Vollmer, 2009; Vollmer and Schiesser, 2009). Most smaller German VVs_ especially in rural areas—still have the UV and MV forms (Dümmler, 2015). Unlike large cities, small cities and rural areas do not have sufficient expertise in PT to take the leading role in their VVs.

All six case studies in this article are AVs. Table 1 shows the approximate allocation of functions among government jurisdictions, the VV executive body, and PT firms. As noted below, there are variations among VVs in the responsibilities at each level. But this table shows the general division of tasks. 


\begin{tabular}{|c|l|}
\hline Level of VV & \multicolumn{1}{c|}{ Typical Tasks } \\
\hline Government & - Determining overall level of PT services and fares \\
Jurisdictions & $\begin{array}{l}\text { - Setting level of government funding and infrastructure } \\
\text { investment }\end{array}$ \\
& $\begin{array}{c}\text { - Deciding which PT services to tender and under what } \\
\text { conditions }\end{array}$ \\
\hline \multirow{5}{*}{ VV Executive } & - Planning and coordination of PT service levels, routes, \\
Body & $\begin{array}{l}\text { and timetables } \\
\text { - Issuing calls for tender and awarding PT service } \\
\text { contracts } \\
\text { - Integrating fare structure and ticketing } \\
\text { - Distributing fare revenues and government subsidies } \\
\text { among PT firms } \\
\text { - Marketing and public relations } \\
\text { - Setting and monitoring service quality standards } \\
\text { - Long-term planning and coordination of PT } \\
\text { infrastructure projects }\end{array}$ \\
\hline - Running PT services \\
\end{tabular}

Table 1. Typical Allocation of Tasks by Level for Aufgabenträgerverbünde (AVs) Sources: VDV, 2009; Dümmler, 2015; HVV, 2015; MVV, 2012; VRR, 2015; ZVV, 2015; VOR, 2015

As shown in Figure 3, there is mutual feedback among PT firms, government jurisdictions, and the VV executive body. For example, government jurisdictions establish the overall level of PT service, but the VV translates that into specific service levels by mode, route, and schedule- - with crucial input from the PT firms actually providing the service. Similarly, government jurisdictions jointly determine overall subsidy and fare levels, but the VV translates those into a specific fare structure, and PT firms collect those fares. Government jurisdictions determine which services to contract out, but the VV issues the tenders and awards contracts, and PT firms (both within and outside the VV) compete to provide such services. Government jurisdictions determine the overall level and types of infrastructure investment, but with the 
advice of VV planners. In most cases, PT firms directly supervise the projects, which are usually contracted out to construction firms.

These are only generalizations, as there is considerable variation from one VV to another, even within each of the VDV's three categories of VVs (UV, MV, AV). Thus, there are also exceptions to these generalizations among the six case study VVs. For example, the $€ 365$ annual PT ticket in Vienna was a specific condition of the Green Party to form a ruling coalition with the Social Democrats in 2010 (for Vienna’s city-state government), and to continue their coalition in 2016 (Buehler et al., 2017a; Vassilakou, 2015). The city-state government, however, agreed to offset any losses resulting from the low fare, accommodating concerns of PT firms in the Vienna VV (Steinbauer, 2015). Moreover, the VV and PT firms helped implement the new, reduced fare structure. So all three levels worked together (Bohrn, 2015). Hamburg provides another example of exceptions (Berning, 2015; HVV, 2015). PT companies there perform some tasks usually assigned to the VV. For example, PT firms in the Hamburg VV provide customer information both online and by phone; sell tickets online and by smart phone (which can be scanned as tickets); handle corporate customers; and print information displayed at bus stops and rail stations (Berning, 2015; HVV, 2015).

The variations in the specific organizational structure and assignment of functions within VVs_ _ even among our case study AVs_-are evidence of the extraordinary flexibility of the VV organizational form, which can be adapted to the specific needs and situation of each region. Notwithstanding these differences in internal organizational structure and assignment of functions, all VVs facilitate cooperation among many government jurisdictions and PT firms in the VV service area. Moreover, they all have the goal of providing fully-integrated PT services, 
one fare structure, and uniform ticketing. From the customer's perspective, that is the most important consideration.

\section{Overview of the six case studies}

As noted earlier, we chose the six oldest and largest VVs in Germany, Austria, and Switzerland as case studies for this analysis. Table 2 provides key background information for the case study VVs. Rhine-Ruhr (VRR) has, by far, the largest population in its service area (7.7m), followed by Berlin-Brandenburg (VBB) (5.9m). The VVs in Hamburg (HVV) (3.4m), Munich (MVV) (2.9m), and Vienna (VOR) (2.8m) have roughly the same service area populations. Zurich’s Verbund (ZVV) has the smallest population (1.5m), and its central city’s population $(0.4 \mathrm{~m})$ is much less than for the other central cities. Correspondingly, the city of Zurich's land area and that of its VV are small compared to the other five cities and their VVs. We include Zurich, however, because it is the largest and most important city in Switzerland, and it has the country’s only VV. Of the core cities, Munich, Vienna, and Zurich have the highest population densities, almost twice as high as in Hamburg and the Rhine-Ruhr cities. Those core city densities are much higher than the outlying parts of the VV service areas, with the biggest differences in Berlin-Brandenburg (45:1) and Vienna (33:1). The Berlin and Vienna VVs include the entire federal states that surround them, Brandenburg and Lower Austria, which are largely rural, thus accounting for the low density in their overall service areas (see Table 2). 


\begin{tabular}{|c|c|c|c|c|c|c|c|c|c|c|c|c|c|c|}
\hline \multirow[b]{2}{*}{$\begin{array}{l}\text { Verkehrs- } \\
\text { verbund }\end{array}$} & \multirow[b]{2}{*}{$\begin{array}{l}\text { Core } \\
\text { City }\end{array}$} & \multirow[b]{2}{*}{$\begin{array}{c}\text { Year } \\
\text { Operations } \\
\text { Began }\end{array}$} & \multicolumn{3}{|c|}{$\begin{array}{c}\text { Population } \\
\text { (millions) }\end{array}$} & \multicolumn{3}{|c|}{$\begin{array}{c}\text { Land Area } \\
\left(\mathrm{km}^{2}\right)\end{array}$} & \multicolumn{3}{|c|}{$\begin{array}{c}\text { Population Density } \\
\left(\text { per } \mathbf{k m}^{2}\right)\end{array}$} & \multicolumn{3}{|c|}{$\begin{array}{c}\text { Motorization Rates } \\
\text { (Cars per 1,000) }\end{array}$} \\
\hline & & & $\begin{array}{c}\text { Service } \\
\text { Area }\end{array}$ & $\begin{array}{l}\text { Core } \\
\text { City }\end{array}$ & $\begin{array}{l}\text { Core City } \\
\text { Share (\%) }\end{array}$ & $\begin{array}{l}\text { Core } \\
\text { City }\end{array}$ & $\begin{array}{l}\text { Service } \\
\text { Area }\end{array}$ & $\begin{array}{l}\text { Core City } \\
\text { Share (\%) }\end{array}$ & $\begin{array}{l}\text { Core } \\
\text { City }\end{array}$ & $\begin{array}{c}\text { Outside } \\
\text { of Core } \\
\text { City }\end{array}$ & $\begin{array}{c}\text { Service } \\
\text { Area }\end{array}$ & $\begin{array}{l}\text { Core } \\
\text { City }\end{array}$ & $\begin{array}{c}\text { Outside } \\
\text { of Core } \\
\text { City }\end{array}$ & $\begin{array}{c}\text { Ratio } \\
\text { Region/City }\end{array}$ \\
\hline HVV & Hamburg & 1967 & 3.4 & 1.8 & 53 & 755 & 8,616 & 9 & 2,358 & 200 & 389 & 404 & 590 & 1.46 \\
\hline MVV & \begin{tabular}{|l|} 
Munich \\
\end{tabular} & 1972 & 2.9 & 1.4 & 50 & 311 & 5,530 & 6 & 4,502 & 287 & 524 & 493 & 796 & 1.61 \\
\hline VOR & Vienna & 1984 & 2.8 & 1.8 & 62 & 415 & 8,841 & 5 & 4,241 & 129 & 322 & 394 & 960 & 2.44 \\
\hline $\mathrm{ZVV}$ & Zurich & 1990 & 1.5 & 0.4 & 26 & 88 & 1,839 & 5 & 4,432 & 651 & 832 & 368 & 583 & 1.58 \\
\hline VBB & Berlin & 1999 & 5.9 & 3.4 & 58 & 892 & 30,374 & 3 & 3,812 & 84 & 193 & 324 & 542 & 1.67 \\
\hline VRR & 19 cities & 1980 & 7.7 & 4.9 & 64 & 2,312 & 7,305 & 32 & 2,119 & 561 & 1,054 & 497 & 547 & 1.10 \\
\hline
\end{tabular}

Table 2. Overview of Population, Area, and Motorization in Six Case Study Verkehrsverbünde, 2015

Sources: (Buehler et al., 2017b; Buehler et al., 2015; HVV, 1990-2015; MVV, 1990-2015; VBB, 2000-2015; VOR, 1990-2015; VRR, 1990-2016; ZVV, 2015)

The most striking variation in motorization rates is in Vienna: The city itself has the third lowest rate of car ownership among the core cities, but its outlying VV area has the highest rate (960), well ahead of Munich (796), and almost twice the levels in the other VVs. The suburban area around Vienna has high levels of car ownership and use, as confirmed by a recent case study of Vienna’s transport policies (Buehler et al., 2017a). The car-dependence in Lower Austria is partly due to the low population density there. The city-states of Vienna and Berlin both have low car ownership rates, thus promoting PT use, while their suburban areas have high car ownership, making it more difficult and expensive to provide PT service and attract riders there. Munich’s surrounding region has a high motorization rate (796), second only to Vienna’s suburbs, although Munich’s suburban density is more than twice as high as Vienna's. The explanation is probably related to the high average incomes in the part of Bavaria surrounding Munich compared to the much lower average incomes in the rural states surrounding Vienna and especially Berlin. Rhine-Ruhr is an exception to the other VVs due to its polycentric service area, which is filled with cities, towns, and suburbs, leading to a suburban density that is almost as high as around Zurich, and to a motorization rate that only slightly higher than in the 19 core cities of the VRR region (547 vs. 497). 
Table 3 highlights the complex governance structure of the six VVs. Those in Vienna (VOR) and Hamburg (HVV) each include the active involvement of three federal states, compared to two in Berlin-Brandenburg and only one in the other three VVs. Vienna's VV is an exception because it is governed solely by the three states it serves. City, suburb, county, and district governments are involved in most of the VVs. The governing board of the BerlinBrandenburg VV includes five cities (Berlin and four much smaller cities in Brandenburg). The governing board of the Rhine-Ruhr VV includes 19 major cities—reflecting the polycentric nature of its service area. The decentralized governmental structure in Switzerland accounts for the 168 suburban districts involved in governance of the $\mathrm{ZVV}$, all of which, however, are in the Kanton of Zurich.

\begin{tabular}{|c|c|c|c|c|c|}
\hline & & \multicolumn{4}{|c|}{ Number of Collaborators in Verkehrsverbund } \\
\cline { 3 - 6 } Name & City & States & $\begin{array}{c}\text { Suburban } \\
\text { Counties / } \\
\text { Districts }\end{array}$ & $\begin{array}{c}\text { Large } \\
\text { Cities }\end{array}$ & $\begin{array}{c}\text { Public } \\
\text { Transport } \\
\text { Operators }\end{array}$ \\
\hline MVV & Munich & 1 & 8 & 1 & 55 \\
\hline HVV & Hamburg* & 3 & 7 & 1 & 29 \\
\hline VOR & Vienna* & 3 & 0 & 1 & 41 \\
\hline VBB & Berlin* & 2 & 14 & 5 & 42 \\
\hline ZVV & Zurich & 1 & 168 & 1 & 51 \\
\hline VRR & 19 Cities & 1 & 7 & 19 & 39 \\
\hline
\end{tabular}

Table 3. Overview of Government and Public Transport Agencies Sources: (Buehler et al., 2015; HVV, 1990-2015, 1995-2015; MVV, 1990-2015; VBB, 2000-2015; VOR, 1990-2015; VRR, 1990-2016; ZVV, 2015)

* Hamburg, Berlin and Vienna are not only cities, but also federal states. Thus they appear in both columns.

All six of the case study VVs have a large number of PT firms providing service, ranging from 55 in Munich to 29 in Hamburg. In each of these six VVs, the largest PT firms are publicly owned and operated. The various governments involved in each VV jointly negotiate with PT operators about service levels, fares, revenue distribution, and subsidies. One of the key 
achievements of VVs is bringing together so many different governments and PT operators to provide integrated services, coordinated schedules, and uniform fare structures and ticketing.

\section{Comparison of performance in six case study Verkehrsverbünde, 1990-2016}

As argued above, VVs have provided better PT services by fully integrating them across modes and operators over entire metropolitan areas. This section documents the success of the six case study VVs in raising passenger levels and reducing car dependence by implementing a range of measures to expand and improve PT services while offering increasingly attractive fare structures. Except for Vienna, passenger fare revenues have covered an increasing percentage of PT operating costs in spite of improved service and attractive fare structures. The section concludes with a brief review of the extensive car-restrictive measures in all six VV regions, which have been crucial to discouraging car use and thus encouraging a modal shift to PT.

\subsection{Trends in passenger levels}

The most important goal of VVs has been to increase PT use, and thus to divert trips from the private car. As shown in Table 4, five of the case study VVs have succeeded in raising the total number of annual passenger trips between 1990 and 2015, ranging from 72\% in Hamburg to 32\% in Rhine-Ruhr. Over the shorter period 2000 to 2015, Berlin’s VV attracted 29\% more passengers. These increases in passenger trips from 1990-2016 are a continuation of the increases reported by Pucher and Kurth (1996) for the same VVs over the earlier period 19701990 — except for VBB, which did not yet exist. 


\begin{tabular}{|l|l|c|c|c|c|c|}
\hline Verkehrsverbund & Indicator & $\mathbf{1 9 9 0}$ & $\mathbf{2 0 0 0}$ & $\mathbf{2 0 1 0}$ & $\mathbf{2 0 1 5}$ & \% Increase 1990-2015 \\
\hline \multirow{2}{*}{ HVV (Hamburg) } & Total (million) & 436 & 489 & 676 & 751 & 72 \\
\cline { 2 - 7 } & Per Capita & 169 & 185 & 199 & 220 & 30 \\
\hline \multirow{2}{*}{ MVV (Munich) } & Total (million) & 507 & 547 & 633 & 692 & 36 \\
\cline { 2 - 7 } & Per Capita & 216 & 224 & 234 & 247 & 14 \\
\hline \multirow{2}{*}{ VOR (Vienna) } & Total (million) & 680 & 784 & 908 & 1034 & 52 \\
\cline { 2 - 7 } & Per Capita & 286 & 281 & 324 & 382 & 34 \\
\hline \multirow{2}{*}{ ZVV (Zurich) } & Total (million) & n.a. & 1061 & 1260 & 1365 & $29^{*}$ \\
\cline { 2 - 7 } & Per Capita & n.a. & 177 & 214 & 231 & $31^{*}$ \\
\hline \multirow{2}{*}{ VRR (Rhine-Ruhr) } & Total (million) & 384 & 449 & 582 & 620 & 61 \\
\cline { 2 - 7 } & Per Capita & 321 & 371 & 423 & 442 & 38 \\
\cline { 2 - 7 } & Potal (million) & 981 & 1065 & 1244 & 1291 & 32 \\
\hline
\end{tabular}

Table 4. Trend in Public Transport Passengers per Year, 1990 -2015

Sources: (Buehler et al., 2015; HVV, 1990-2015; MVV, 1990-2015; VBB, 2000-2015; VOR, 1990-2015; VRR, 19902016; ZVV, 2015)

* VBB was not operational until 1999. Thus the percentage change for VBB shown in the table is only for the period 2000-2015.

Some of the growth in total passenger trips in Hamburg, Munich, Vienna, and Zurich was due to expansion of the VV area as well as population growth. The increases in per-capita passenger trips were considerably smaller, ranging from $38 \%$ in Zurich to $14 \%$ in Munich. The reverse was true, however, in Rhine-Ruhr, which lost population, yet increased ridership, so that trips per capita rose by 38\% vs. 32\% in total. Similarly, per capita trips in Berlin-Brandenburg (VBB) rose by $31 \%$ vs. $29 \%$ in total.

Whatever the variations among VVs, the main point of Table 4 is that all six VVs were successful at increasing passenger trips, both in total and per capita. As noted below, there are several reasons for the increase in passengers: more and improved service; more attractive fares, esp. for regular riders; car-restrictive measures such as parking limitations and higher fees; and rising costs of gasoline (petrol).

\subsection{Trends in service quantity and quality}

One obvious way to raise PT ridership is to increase the amount of PT service provided and to improve its quality, as confirmed by many studies (Bresson et al., 2003; Cervero, 1990; 
Holmgren, 2007; Litman, 2004, 2017b; Paulley et al., 2006; Redman et al., 2013; Webster and Bly, 1981). Most of these studies find that service quality—especially among car-owning households—is more important than fare structure in promoting PT usage. Time of travel is crucial, often the main determinant of modal choice between PT and the private car. Moreover, waiting time and transfer time are valued considerably more than in-vehicle time. These findings confirm the need to provide frequent, on-time services, with convenient and reliable transfers among routes and modes. That sort of high-quality, fully-integrated service is the goal of all VVs and indeed their main reason for existing (VDV, 2009).

As shown in Table 5, all of the VVs except Berlin-Brandenburg increased the total amount of service from 1990 to 2015, as measured by place km of service (including seating and standing capacity within vehicles). Indeed, Hamburg almost doubled service (+93\%), with similarly large increases in Munich (+88\%) and Zurich (+75\%). In contrast, Rhine-Ruhr increased service by only $18 \%$. Over the shorter period 2000-2015, there was almost no change in Berlin-Brandenburg (-1\%). Similar to the changes in passenger levels in Table 4, the increases in service levels are much smaller when calculated on a per capita basis: $+59 \%$ in Munich, $+50 \%$ in Zurich, $+46 \%$ in Vienna, and only $+13 \%$ in Rhine-Ruhr. Berlin's per-capita service again remained almost unchanged $(+1 \%)$. 


\begin{tabular}{|l|l|c|c|c|c|}
\hline Verkehrsverbund & Indicator & $\mathbf{1 9 9 0}$ & $\mathbf{2 0 0 0}$ & $\mathbf{2 0 1 5}$ & $\mathbf{\%}$ Change 1990-2015 \\
\hline \multirow{2}{*}{ HVV (Hamburg) } & Total (billion) & 19 & 23 & 37 & +93 \\
\cline { 2 - 6 } & Per Capita & 7,680 & 8,750 & 11,080 & +44 \\
\hline \multirow{2}{*}{ MVV (Munich) } & Total (billion) & 19 & 29 & 36 & +88 \\
\cline { 2 - 6 } & Per Capita & 8,234 & 11,948 & 13,103 & +59 \\
\hline \multirow{2}{*}{ VOR (Vienna) } & Total (billion) & 25 & 32 & 44 & +47 \\
\cline { 2 - 6 } & Per Capita & 10,588 & 12,490 & 15,420 & +46 \\
\hline \multirow{2}{*}{ VBB (Berlin) } & Total (billion) & n.a. & 54 & 53 & -1 \\
\cline { 2 - 6 } & Per Capita & n.a. & 9,041 & 9,150 & +1 \\
\hline \multirow{2}{*}{ ZVV (Zurich) } & Total (billion) & 14 & 20 & 25 & +75 \\
\cline { 2 - 6 } & Per Capita & 11,984 & 16,369 & 17,939 & +50 \\
\hline \multirow{2}{*}{ VRR (Rhine-Ruhr) } & Total (billion) & 34 & 40 & 40 & +18 \\
\cline { 2 - 6 } & Per Capita & 4,610 & 5,530 & 5,195 & +13 \\
\hline
\end{tabular}

Table 5. Trend in Place Kilometers of Public Transport Service per Year, 1990 -2015

Sources: (Buehler et al., 2015; HVV, 1990-2015, 1995-2015; MVV, 1990-2015; VBB, 2000-2015; VOR, 1990-2015; VRR, 1990-2016; ZVV, 2015)

Although quality of service is difficult to measure, the latest available survey information indicates that most residents of the core cities of the six case study VVs were "satisfied” or "very satisfied” with the overall quality of PT service. The European Union’s 2013 Eurobarometer found the highest rates of satisfaction in Zurich (97\%) and Vienna (95\%), compared to 88\% in Hamburg, 86\% in Munich, and 84\% in Berlin (EU Commission, 2009 and 2013). Essen, the largest city in the Rhine-Ruhr conglomeration, got the lowest rating: 72\%, but still an overwhelming majority of residents. Zurich, Vienna, Hamburg and Munich were among the top ten best-rated PT systems among the 79 EU cities surveyed by Eurobarometer in 2013, with a satisfaction rate ranging from a high of $97 \%$ in Zurich to a low of 32\% in Rome.

The increased quantity of service reported in Table 5 has fostered increased quality of service in several respects. New and expanded bus and rail routes have increased the geographic coverage of service, providing greater connectivity and more travel options. In most of the VVs, bus and rail services have become more frequent, often in regular, easy-to-remember intervals such as every 10, 15 or 20 minutes. In addition, all of the case study VVs have modernized 
buses and rail vehicles and have invested heavily in infrastructure improvements such as upgraded or new stations, rights of way, safety systems, and maintenance facilities.

The six case study VVs design route schedules to minimize transfer times between different modes and lines. Schedule planning focuses on the entire trip, from origin to destination—-taking transfers explicitly into account—with the goal of minimizing both total travel time and problematic transfers. The synchronization of route schedules and coordinated location of station stops integrate different public transport modes: S-Bahns and regional rail primarily serve longer trips from the suburbs; U-Bahns generally serve trips in high-density city corridors; trams and buses cover intermediate distances and serve as feeders and distributors to S-Bahn and U-Bahn stations.

Improved technology and targeted infrastructure investments have facilitated transfers between PT modes and lines, with better coordinated timing and proximity, thus reducing waiting times and walking distances for transfers (Buehler and Pucher, 2011a; Buehler et al., 2017b). In the 1970s, for example, shortly after the founding of Munich’s VV, a 4km tunnel with five stations was built to connect the two main long-distance rail terminals and to facilitate transfers between the U-Bahn, the S-Bahn, and long distance rail, each running on a different level of the tunnel (MVV, 2012). Escalators between platforms at different levels make vertical transfers easy among these three types of PT—as well as street-level tramways and city buses. Convenient connections among modes are facilitated by coordinated timetables, as well as realtime information displays provided at each level. The multimodal integration provided by this tunnel has been so successful that a second, larger tunnel is now being constructed to expand capacity (MVV, 2017). 
Regionwide VVs are an ideal platform for fully-integrating real-time information systems, both online (via computers and smartphones) and with digital displays at PT station stops and on PT vehicles. Online trip planners suggest the best options, considering all available modes and routes, regardless of PT operator. Integrated information makes it easier for passengers to use the VV's integrated services.

Not only are PT services better coordinated with each other, but there is also better coordination of PT with cars and bikes. Reflecting the continuing decentralization of metropolitan areas, there is an increasing demand for trips from low-density suburbs, which are difficult to serve with PT (Buehler and Pucher, 2012). Thus, all six VVs have been greatly expanding the number and size of park-and-ride lots for PT riders accessing stations by car (Buehler et al., 2017b). In addition, the six VVs have increased the number and quality of bike parking facilities, which are often sheltered and sometimes secure, as in the case of full-service bike stations located directly adjacent to major PT stations (Buehler et al., 2017b). Taking multimodal integration a step further, many car-sharing and bike-sharing stations are located next to U-Bahn or S-Bahn stations. Bike-sharing and car-sharing agencies are increasingly working together with VVs to offer special monthly or annual tickets that include membership in bikesharing or car-sharing programs.

\subsection{Fare policy}

Several studies have examined the impacts of fares on PT demand (Bresson et al., 2003; Cervero, 1990; FitzRoy and Smith, 1998; Goodwin, 1992; Litman, 2004, 2017b; Matas, 2004; Paulley et al., 2006). They all find that higher fares discourage PT ridership, but that fare elasticities are considerably higher in the long-run than in the short-run, and vary by income, 
employment status, car ownership, trip purpose, time of day, city size, type of ticket, and PT mode.

VVs have greatly improved the convenience of ticketing while providing large discounts for regular riders. Nevertheless, fares have generally increased in all six of the VVs from 1990 to 2015. Table 6 shows the average price per trip for each VV, calculated as total revenue from all ticket types, divided by total passenger trips, and expressed in inflation-adjusted, constant 2015 Euros. Over the entire 25-year period, average fares per trip increased faster than inflation in all of the VVs except for Vienna, where fares rose $12 \%$ less than inflation. The largest fare increase was in Munich (46\% more than inflation), with smaller increases in Rhine-Ruhr (33\%), Zurich (27\%), and Hamburg (12\%).

Importantly, PT fares have increased less than gasoline (petrol) prices over the same period. The difference was smallest in Munich (46\% vs. 55\%) and greatest in Vienna (-12\% vs. +33\%). Thus, using public transport became relatively cheaper than driving a car, providing an increasing financial incentive to take PT instead of driving. Studies emphasize the crucial role of petrol prices in determining PT demand (FitzRoy and Smith, 1998, 1999; Frankena, 1978; Goodwin, 1992; Litman, 2004; Matas, 2004; Paulley et al., 2006). Indeed, the cross-price elasticity of PT demand with respect to petrol price is usually found to be greater than the direct price elasticity of PT demand. 


\begin{tabular}{|c|c|c|c|c|c|c|c|c|}
\hline & \multicolumn{6}{|c|}{ Constant 2015 Euros } & \multicolumn{2}{|c|}{$\begin{array}{c}\text { \% inflation adjusted change } 1990 \\
2015\end{array}$} \\
\hline & 1990 & 1995 & 2000 & 2005 & 2010 & 2015 & Average fare & Gasoline prices \\
\hline HVV (Hamburg) & 1.02 & 1.06 & 0.93 & 0.97 & 0.98 & 1.17 & +15 & +55 \\
\hline MVV (Munich) & 0.89 & 1.02 & 0.98 & 1.05 & 1.12 & 1.30 & +46 & +55 \\
\hline VOR (Vienna) & 0.77 & 0.70 & 0.71 & 0.71 & 0.69 & 0.67 & -12 & +33 \\
\hline VBB (Berlin) & n.a. & n.a. & 0.83 & 0.85 & 0.91 & 1.01 & n.a. & +55 \\
\hline ZVV (Zurich) (in SFR) & 0.94 & 0.97 & 1.10 & 1.08 & 1.13 & 1.20 & +27 & +55 \\
\hline VRR (Rhine-Ruhr) & 0.53 & 0.48 & 0.61 & 0.56 & 0.64 & 0.70 & +33 & +55 \\
\hline
\end{tabular}

Table 6. Trend in Average Revenue per Passenger Trip, 1990 -2015

Sources: (BMVBS, 1991-2016; IEA, 2016; VOR, 1990-2015; ZVV, 2015)

Note: SFR refers to Swiss Francs. In 2015, one Swiss Franc was worth roughly one Euro (€0.95)

The impact of the reduced price of PT relative to car use was largest in Vienna, where the PT mode share of trips rose from 29\% in 1993 to 39\% in 2014, while the car mode share fell from $40 \%$ to $27 \%$, and bike mode share doubled from 3\% to 6\% (Buehler et al., 2017b). By comparison, PT mode share in Munich fell slightly from 24\% in 1989 to 23\% in 2011. But car mode share fell much more, from 40\% to 33\% (Buehler et al., 2017b). Bike mode share rose from $12 \%$ to $17 \%$, and walk mode share rose from $27 \%$ to $31 \%$, partly reflecting the very low cost of these two non-motorized modes, especially compared to the rising real price of both car use and PT in Munich.

The average fares shown in Table 6 do not reveal the large variety of ticket types and prices in each of the six VVs, all of which offer substantial discounts from the regular one-way ticket price. Studies show that season tickets greatly increase PT ridership, not only through their discounts, but also by making the marginal cost of any individual trip zero (FitzRoy and Smith, 1999; Matas, 2004; Redman et al., 2013). Figure 4 shows the percentage discounts for monthly and annual tickets, as well as for seniors, schoolchildren, and university students. We calculated the discounts relative to the cost of making an average of 10 trips per week (520 per year) using regular one-way tickets. All ticket prices apply to trips made within the inner zone, usually including the entire core city, e.g. within the city boundaries of Vienna. For persons 
making more than 10 trips per week, the shown discounts understate the actual percentage discount. For persons making fewer than 10 trips per week, the shown discounts overstate the actual discount. Especially for monthly and annual tickets, it is likely that ticket holders make more than ten trips a week because the marginal cost of any given trip is zero once the monthly or annual ticket is purchased.

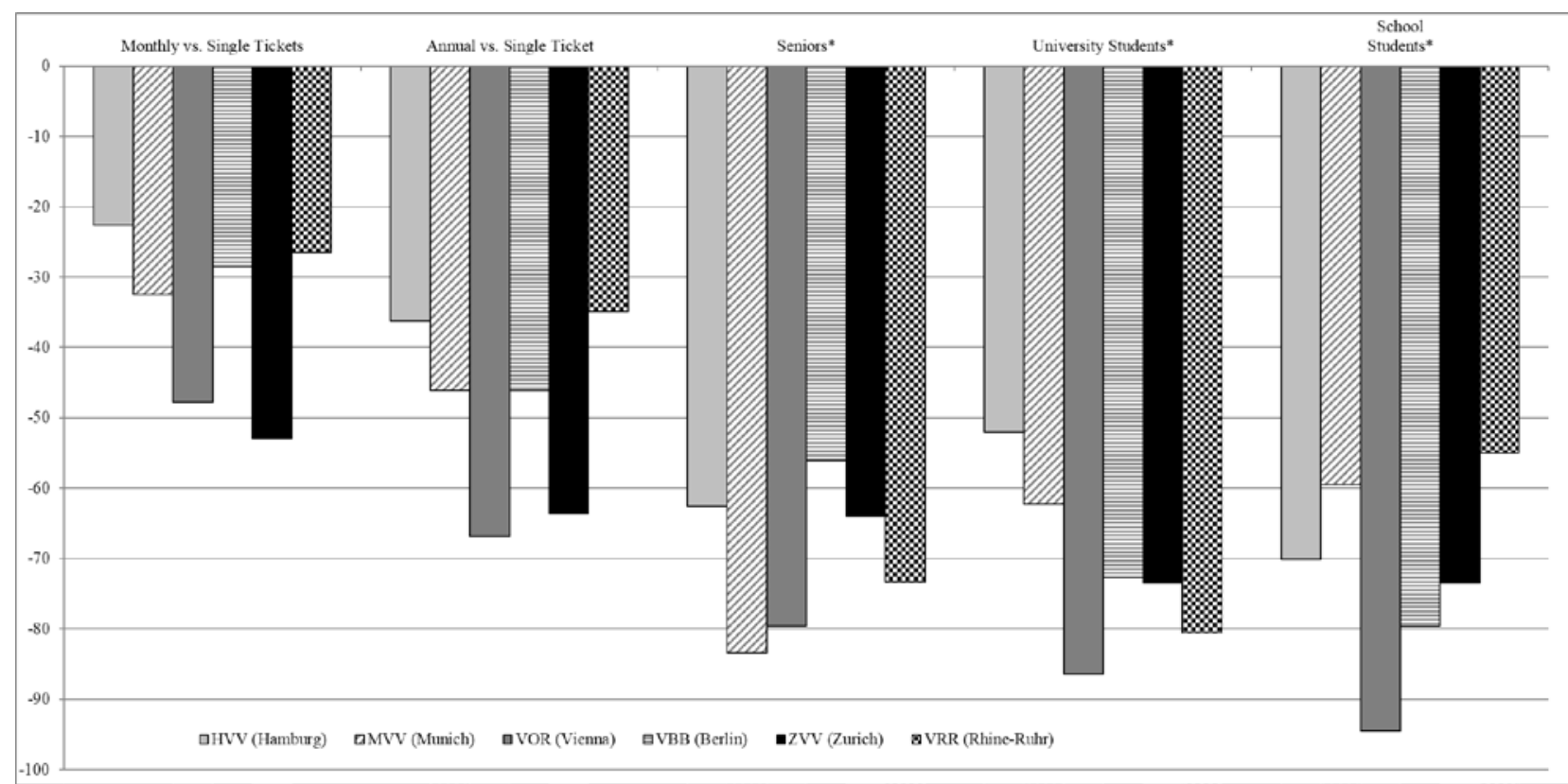

Figure 4. Discounts for Monthly, Annual, and Special Group Tickets, 2016

Sources: (HVV, 1990-2015; MVV, 1990-2015; VBB, 2000-2015; VOR, 1990-2015; VRR, 1990-2016; ZVV, 2015) Note: These calculations assume an average of 10 trips per week. Persons making more than 10 trips per week receive a larger discount than shown in the table, while those making fewer than 10 trips a week receive a smaller discount. Furthermore, the calculated fare discounts are based on travel within the inner zones of the Verkehrsverbund, usually delineated by the boundaries of the city proper. Trips beyond the city boundary require higher fares, which usually increase with distance from the city center. Finally, the Verkehrsverbünde have slightly different prerequisites for special discounts and conditions for use of different tickets.

* Seniors in Zurich do not receive an additional discount for the annual ticket. Moreover, Zurich does not have a special university or school discount, but instead offers discounted tickets to people 25 and younger.

We assumed 10 trips per week to provide the same basis of comparison for all VVs. As shown in Table 4, however, the average number of PT trips per capita in Zurich (442) and Vienna (382) is almost twice as high as the averages in the four German VVs, ranging from 247 in Munich to 168 in Rhine-Ruhr. Thus, the percentage discounts shown for Vienna and Zurich are probably underestimates, while those in the German cities may be overestimates. 
In spite of those qualifications about the estimates shown in Figure 4, they highlight the deep fare discounts offered in all six of the VVs. Monthly ticket discounts range from $53 \%$ in Zurich and 48\% in Vienna to 26\% in Rhine-Ruhr and 23\% in Hamburg. Annual ticket discounts range from 67\% in Vienna and 64\% in Zurich to 36\% in Hamburg and 35\% in Rhine-Ruhr. It is notable that Zurich and Vienna, with by far the deepest discounts on monthly and annual tickets, also have, by far, the highest per capita PT trips. There are also deep discounts for special groups: ranging from $83 \%$ to $56 \%$ for seniors, from $86 \%$ to $52 \%$ for university students, and from $95 \%$ to $55 \%$ for school students. In every case, Vienna offers the greatest discounts for these groups, again helping to explain the high level of PT use in Vienna. PT use in the VVs is encouraged not only through the discounted prices but also through the structure of the pricing. As noted above, the marginal user cost of any particular trip is zero once a monthly, annual, senior, student, or school ticket is purchased.

\subsection{Operating cost coverage from fares vs subsidies}

In spite of service expansion and attractive fare structures, the percentage of operating costs covered by fare revenues rose from 1990 to 2016 in most of the VVs: from 58\% to 80\% in Munich, from 35\% to 52\% in Rhine-Ruhr, from $62 \%$ to $72 \%$ in Hamburg, and from $57 \%$ to $65 \%$ in Zurich (see Table 7). Vienna's VV was the only one to experience a decline, from $63 \%$ to $55 \%$, almost certainly due to the sharp decrease in monthly (-10\%) and annual ticket (-20\%) prices in 2012 and the increase in operating costs to provide the additional service required to accommodate the large increase in passengers (Buehler et al., 2017a). 


\begin{tabular}{|l|c|c|c|}
\hline & \multicolumn{2}{|c|}{ Verkehrsverbund } & Core City \\
\hline & $\mathbf{1 9 9 0}$ & $\mathbf{2 0 1 6}$ & $\mathbf{2 0 1 6}$ \\
\hline HVV (Hamburg) & 62 & 72 & 90 \\
\hline MVV (Munich) & 58 & 80 & 100 \\
\hline VOR (Vienna) & 63 & 55 & 69 \\
\hline VBB (Berlin) & n.a. & 55 & 74 \\
\hline ZVV (Zurich) & 57 & 65 & 71 \\
\hline VRR (Rhine-Ruhr) & 35 & 52 & n.a. \\
\hline
\end{tabular}

Table 7. Percentage of Operating Costs Covered by Fares, 1990 and 2016

Sources: (HVV, 1990-2015; MVV, 1990-2015; VBB, 2000-2015; VOR, 1990-2015; VRR, 1990-2016; ZVV, 2015)

Note: These cost recovery ratios are based on financial statistics supplied directly by the VVs and their core PT operators. They are only roughly comparable because different PT agencies have somewhat different accounting methods for calculating costs and revenues. Revenues include government reimbursements to cover costs of reduced fares for special groups, such as seniors, school children, and university students. Also included in revenues are other sources of income, such as advertising and rental of space in or near stations, which can vary considerably from one system to another. The overall trend of increased cost recovery ratios in the German VVs is corroborated by a national aggregate increase in Germany from 59\% in 1990 to 77\% in 2015 (VDV, 2001-2017).

In all the VVs for which data are available, the percentage cost coverage in 2015 was much higher in the core operating PT system than for the VV as a whole. The largest difference was in Munich (100\% vs. 80\%), but almost as large in Berlin (74\% vs 55\%) and Hamburg (90\% vs. 72\%). There was a considerable gap in Vienna as well (69\% vs 55\%) but much less in Zurich (71\% vs. 65\%). The much more unprofitable services in the outlying parts of each VV are due to lower-density land use, longer trip distances, fewer passengers per vehicle, and the need to provide park-and-ride services for car access to stations.

As noted in other research on the topic of VVs, the larger subsidies needed to provide comprehensive regional service, including suburban and rural areas, are not necessarily a disadvantage of VVs (Cervero, 1998; Dümmler, 2015; Koch and Newmark, 2017; Mees, 2010; Pucher and Kurth, 1996; Topp, 1989; Vuchic, 1999). Such services to outlying areas are inevitably more expensive to provide, but they are necessary for truly comprehensive regional coverage to help unify the greater metropolitan area. Such rural services also provide crucial mobility to those without cars or who cannot drive (e.g. children and some seniors). 
Similarly, the much lower cost coverage in Vienna, both for the core city and for the entire VV, must be evaluated in light of the extremely attractive fares offered there, which have greatly increased PT usage while reducing the share of trips by car from $40 \%$ in 1990 to $27 \%$ in 2015. That decline in car mode share was greater in Vienna than in any other large European city (Buehler et al., 2017a). To some extent, the setting of fare and subsidy levels is a political decision reflecting the willingness of politicians and their constituents to encourage PT use on the basis of the external social, environmental, and economic benefits of PT (Banister and Thurstain-Goodwin, 2011; Litman, 2017a; Parry and Small, 2009; Topp, 1989; Vuchic, 1999).

As already shown in Table 7, all of the case study VVs except for Vienna raised the share of operating costs covered from passenger fares. There are two reasons for rising cost recovery ratios from 1990-2015: higher passenger fare revenues and lower operating costs. Revenue growth was due to increased average fares in all the VVs except Vienna, combined with increases in the number of passenger trips. Operating costs were reduced through a wide variety of measures taken mostly by individual PT firms within each of the VVs, but sometimes coordinated by the VV (Buehler and Pucher, 2011a). These cost-cutting measures included: organizational restructuring and outsourcing to newly founded subsidiaries; cutting employee benefits and freezing salaries; increasing work hours, using part-time employees, expanding job tasks, and encouraging retirement of older employees; cooperation with other agencies to share employees, vehicles, and facilities; cutting underutilized routes and services; and buying new vehicles with lower maintenance costs and greater passenger capacity per driver.

The increasing financial sustainability of most VVs over the past 25 years is a sharp reversal of earlier trends reported by Topp (1989) and Pucher and Kurth (1996). For all the VVs existing in 1980 (thus excluding Berlin), cost coverage ratios fell between 1980 and 1993. The 
large increase in operating subsidies needed by the VVs over that earlier period was the main concern of both Topp (1989) and Pucher and Kurth (1996). Thus, it is encouraging that the data from 1990-2015 indicate a significant increase in the financial sustainability of most VVs, although they have continued to expand services and offer attractive fares, which enabled sustained growth in passenger trips over a period of about four decades.

\subsection{Car-Restrictive Policies}

Many studies show that PT demand is boosted by car-restrictive policies that increase the cost of car use and reduce its convenience (Cervero, 1998; Newman and Kenworthy, 1999, 2015; Shoup, 2011; TRB, 2001). As already noted in section 7.3, several researchers have found the cross-price elasticity of PT demand with respect to petrol prices higher than the direct fare elasticity of PT demand. The high prices of petrol in Germany, Austria, and Switzerland are mostly due to federal taxes, which account for about two-thirds of the retail price (Buehler et al., 2017b). Federal taxes and fees on car purchases and ownership increase the cost of having a car, thus indirectly discouraging car use as well. Driver licensing is regulated at the federal level in all three countries, with expensive driving lessons and strict testing required for obtaining a license. These national policies lead to a high base cost of car ownership and use (Buehler et al., 2017b).

Local government policies add further to the cost of driving, primarily through parking charges (Buehler et al., 2017a; Shoup, 2011). Cities and towns in each of the six VV service areas also impose restrictions on the supply of parking, the allowed time of parking, speed limits, and car access to certain zones. Pedestrian zones in most cities and towns in the six VV service areas prohibit car use. Traffic-calmed residential streets make car use slower (30km/hr or less), more circuitous, and less convenient. Limitations on new roadway construction in recent 
decades have increased congestion, reduced travel speed, and thus deterred car use as well (Buehler et al., 2017b; TRB, 2001; UN Habitat and European Union, 2016). Thus, all six of the case study VVs have benefited from complementary policies that indirectly encourage PT use by discouraging car use.

\section{Conclusions and key lessons of Verkehrsverbünde}

The most important conclusion to be drawn from the preceding analysis is that the $\mathrm{VV}$ is an extremely successful organizational model for the provision of integrated PT services over a large metropolitan area, and even beyond that, including entire surrounding states. Its success is most evident in the spread of VVs to encompass almost all of Germany, all of Austria, and the largest urban area in Switzerland. Other indices of success include increased quantity and quality of service, rising passenger levels, reduced subsidy needs as a percent of operating costs, and an overall PT mode share that has been stable or rising in spite of increasing rates of car ownership and driver licensing of the German, Austrian, and Swiss populations. Another indicator of success is the falling share of trips by car, a key goal of urban transport policy in European cities: $40 \%$ to $27 \%$ in Vienna; $39 \%$ to $30 \%$ in Zurich, $40 \%$ to $33 \%$ in Munich, $48 \%$ to 42\% in Hamburg, and 35\% to 30\% in Berlin. Those declines would not have been possible without an attractive package of well-coordinated PT, cycling, and walking alternatives to the car.

The VV model has spread quickly because it is adaptable to the different degrees and types of integration needed in different kinds of situations. The six VV examined in this article are all fully-integrated systems but serve different kinds of areas. The urban and suburban service areas of the Munich and Hamburg VVs are more narrowly delineated and more compact than the large, sprawling service areas of the Vienna and Berlin VVs, which include extensive 
rural areas. Rhine-Ruhr is extremely polycentric while the other five VVs are monocentric. VVs also vary in their internal organization, with state and local governments running the decision-making VV boards in almost all large urban areas, while PT operators run VV boards in smaller cities and towns. Thus, the VV model is actually a range of organizational structures but with the same outcome of fully integrated services, fares, and ticketing. The flexibility of its internal organizational form makes it more adaptable, helping to explain its widespread adoption. One puzzling issue remains: Why the VV model has not spread beyond Germanspeaking countries? To some extent, regional PT organization has simply taken a different form and name in other countries (Hrelja et al., 2016; Sørensen and Longva, 2011; UITP, 2014; van de Velde, 1999, 2001; VDV, 2009). Danish and Swedish metropolitan areas, for example, also have integrated PT, but coordinated at the county level of government, which is dominant. In the Netherlands, coordination is at the national level, made possible by the much smaller size of the country. There is some national coordination in Switzerland for the same reason. Except for the one VV in Zurich, most of Swiss regions are served by less fully-integrated Tarifverbünde, which coordinate fares and ticketing (Vollmer and Schiesser, 2009). That limited regional coordination is supplemented, however, by the Swiss federal government, which provides discounted nation-wide annual tickets and coordinates schedules for intercity and regional rail services (Petersen, 2016; VDV, 2009).

American metropolitan areas have similar federal structures to those in Germany, Austria, and Switzerland, with spatial fragmentation among different cities, counties, administrative regions, and states. Political scientists have documented the much greater independence and rivalry among American local and state governments compared to the cooperation and consensus-seeking characteristic of the German federal structure (DiGaetano 
and Strom, 2003; Doering, 2000; Kelemen, 2015). That may explain the unwillingness of local and state governments in the USA to cooperate as closely as necessary in a VV. The resulting lack of PT integration in American urban areas has seriously harmed the overall quality and effectiveness of PT, while helping to explain its enormous subsidy requirements (APTA, 2017; Buehler and Pucher, 2011a; TRB, 2001).

As exemplified by the example of the USA, full integration of PT is not always possible, in spite of the VVs flexibility to adapt to very different situations. The crucial precondition for a VV is the willingness of local governments to work together to improve PT services in their region. Provided that precondition is met, however, VVs would be feasible in many of the world's metropolitan areas. 
Acknowledgement: This research was funded in part by the U.S. Department of Transportation's Research and Innovative Technology Administration (RITA), through the MidAtlantic University Transportation Center (MAUTC) (DTRT12-G-UTC03). Mariia Zimmerman, a visiting fellow at Virginia Tech, and Kyle Lukacs, a graduate assistant at Virginia Tech, collaborated on the MAUTC project by conducting the San Francisco and Washington, DC case studies and by providing feedback on the German, Austrian, and Swiss case studies conducted by Ralph Buehler and presented in this article. Mariia Zimmerman also conducted in-person interviews in Berlin and Vienna for the case studies of those cities. Bryan Botello, a graduate assistant at Virginia Tech, created Figure 2, the GIS map of Verkehrsverbund expansion. Supplemental financing for the project was provided by the Volvo Research and Educational Foundations, through Harvard University (OP-2012-03). The authors would like to thank the following individuals in the case study cities for their help with the research: Eike Arnold and Axel Steins (Berlin); Marina Berning and Reinhard Merckens (Hamburg), Beate Brennauer and Juergen Kotzmeier (Munich); Sabine Tkatzik (Rhein Ruhr); Thomas Bohrn and Markus Ossberger (Vienna); Peter Nordenson (Zurich); and Till Ackermann and Nils Laschinsky (German PT Association-VDV). 


\section{References}

APTA (2017) APTA Fact Book 2016. American Public Transportation Association, Washington, DC

Banister, D. (2005) Unsustainable transport : city transport in the new century. Routledge, London ; New York.

Banister, D. (2011) 'Cities, Mobility and Climate Change', Journal of Transport Geography, 19(pp. 1538-1546

Banister, D., Givoni, M. (2010) Integrated Transport: From Policy to Practice. Routledge, London, UK.

Banister, D., Thurstain-Goodwin, M. (2011) 'Quantification Of The Non-Transport Benefits Resulting From Rail Investment', Journal of Transport Geography, 19(2), pp. 212-223

Baron, P. (1995) 'Transportation in Germany: A historical overview', Transportation Research Part A: Policy and Practice, 29(1), pp. 9-20

Barth, S. (2013) 'Regionalisierungsgesetz des Bundes und ÖPNV-Gesetze der Länder', in Baumeister, H. (ed) Recht des OEPNV, DVV Media, Hamburg, Germany.

Berning, M. (2015) 'Phone Interview with Member of HVV Management', in Buehler, R. (ed), Hamburg, Germany.

BFS (2017) Mobility and Transport 2015. Bundesamt fuer Statistik/Swiss Federal Office for Statistics, Bern, CH.

BMVBS (1991-2016) 'Verkehr in Zahlen. German transport in figures', German Federal Ministry of Transportation and Urban Development, Berlin.

BMVIT (2017) Oesterreich Unterwegs. BMVIT, Vienna, Austria.

Bohrn, T. (2015) 'Personal Interview with Managing Director, Vienna Regional Public Transport Association', in Buehler, R. (ed), Vienna, Austria.

Bormann, R., Bracher, T., Dümmler, O., Dünbier, L., Haag, M., Holzapfel, H., Kunst, F., Mietzsch, O., Mirbach, J., Mossakowski, H., Ubbelohde, J.H., Werner, J., Zoubek, H. (2010) 'Neuordnung der Finanzierung des Öffentlichen Personennahverkehrs:

Bündelung, Subsidiarität und Anreize für ein zukunftsfähiges Angebot', Friedrich-EbertStiftung,, Bonn, Germany.

Bresson, G., Dargay, J., Madre, J.L., Pirotte, A. (2003) 'The main determinants of the demand for public transport: a comparative analysis of England and France using shrinkage estimators', Transportation Research Part a-Policy and Practice, 37(7), pp. 605-627

Bruehweiler, D., Schurter, W., Rey, G., Weiss, T. (2015) '25 Jahre Zuercher S-Bahn', Eisenbahn Revue, 6(1), pp. 283-293

Bruun, E. (2007) Better transit systems. APA Planners Press, Washington, DC.

Buehler, R., Pucher, J. (2011a) 'Making public transport financially sustainable', Transport Policy, 18(1), pp. 126-138

Buehler, R., Pucher, J. (2011b) 'Sustainable Transport in Freiburg: Lessons from Germany’s Environmental Capital', International Journal of Sustainable Transport, 5(1), pp. 43-70

Buehler, R., Pucher, J. (2012) 'Demand for Public Transport: A Comparison of Germany and the USA', Transport Reviews, 32(5), pp. 541-567

Buehler, R., Pucher, J., Altshuler, A. (2017a) 'Vienna’s Path to Sustainable Transport', International Journal of Sustainable Transportation, 11(4), pp. 257-271 
Buehler, R., Pucher, J., Gerike, R., Goetschi, T. (2017b) 'Reducing car dependence in the heart of Europe: Lessons from Germany, Austria, and Switzerland', Transport Reviews, 37(1), pp. 4-28

Buehler, R., Zimmerman, M., Lukacs, K. (2015) 'Regional Coordination in Public Transportation: Lessons from Germany, Austria, and Switzerland', Mid-Atlantic University Transportation Center, US Department of Transportation, Research and Innovative Technology Administration, Washignton, DC.

Cervero, R. (1990) 'Transit Pricing Research - a Review and Synthesis', Transportation, 17(2), pp. 117-139

Cervero, R. (1998) The transit metropolis. A global inquiry. Island Press, Washington D.C.

DiGaetano, A., Strom, E. (2003) 'Comparative Urban Governance: An Integrated Approach', Urban Affairs Review, 38(3), pp. 356-395

Dimitrou, H.T., Gakenheimer, R. (2011) Urban Transport in the Developing World: A Handbook of Policy and Practice. Edward Elgar, Chetenham, UK.

Doering, T. (2000) 'Finanzfoederalismus in den Vereinigten Staaten von Amerika und in der Bundesrepublik Deutschland im Vergleich', in Wentzel, B., Wentzel, D. (eds) Wirtschaftlicher Systemvergleich Deutschland USA, Lucius and Lucius, Stuttgart.

Dojani, D., Stead, D. (2017) 'The Urban Transport Crisis in Emerging Economies', Springer International Publishing, Cham, Switzerland.

Dümmler, O. (2015) 'Erfassung und Bewertung der Arbeit von Verkehrsverbünden', Fachbereich Bauingenieurwesen, Technische Universität Kaiserslautern, Kaiserslautern, Germany.

Dunn, J. (1980) 'Coordination of Urban Transit Services: The German Model. ', Transportation, 9(1), pp. 33-43

Dunn, J. (1981) Miles to go : European and American transportation policies. MIT Press, Cambridge, Mass.

Eno Foundation (2014) 'Getting to the Route of It: The role of Governance in Regional Transit', ENO Foundation, Washington, DC.

EU Commission (2009 and 2013) 'Quality of Life in Cities (Flash Barometers 277 \& 366)', Brussels, Belgium.

Eurostat (2017) 'Energy and transport in figures', European Commission, Directorate General for Energy and Transport, Brussels, Belgium.

FitzRoy, F., Smith, I. (1998) 'Public transport demand in Freiburg: why did patronage double in a decade?', Transport Policy, 5(3), pp. 163-173

FitzRoy, F., Smith, I. (1999) 'Season tickets and the demand for public transport', Kyklos, 52(2), pp. 219-238

Frankena, M. (1978) 'The demand for urban bus transit in Canada', Journal of Transport Economics and Policy, pp. 280-303

Franz, H.W. (2007) 'Birth of VBB', Nahverkehrs-praxis, 1(1-2), pp. 40-42

Goodwin, P.B. (1992) ' A review of new demand elasticities with special reference to short and long run effects of price charges', Journal of Transport Economics and Policy, 26(2), pp. $155-170$

Hansson, L. (2013) 'Hybrid steering cultures in the governance of public transport: A successful way to meet demands?', Research in Transportation Economics, 39(175-184),

Holmgren, J. (2007) 'Meta-analysis of public transport demand', Transportation Research Part a-Policy and Practice, 41(10), pp. 1021-1035 
Homburger, W., Vuchic, V. (1972) 'Transit Federation -- A Solution for Service Integration', UITP Revue, 2(1), pp. 84-91

Hrelja, R., Monios, J., Rye, T., Isaksson, K., Scholten, C. (2017) 'The interplay of formal and informal institutions between local and regional authorities when creating wellfunctioning public transport systems', International Journal of Sustainable Transportation, 11(8), pp. 611-622

Hrelja, R., Pettersson, F., Westerdahl, S. (2016) 'The Qualities Needed for a Successful Collaboration: A Contribution to the Conceptual Understanding of Collaboration for Efficient Public Transport', Sustainability, 8 pp. 542-557

Hull, A. (2005) 'Integrated transport planning in the UK: From concept to reality', Journal of Transport Geography, 13 pp. 318-328

HVV (1990-2015) Annual Report. Hamburger Verkehrsverbund, Hamburg, Germany.

HVV (1995-2015) 'HVV Facts and Figures', HVV, Hamburg, Germany.

HVV (2015) 'Presentation: HVV—Guidance Organization for Local Public Transport', HVV, Hamburg, Germany.

IEA (2016) 'Energy prices and taxes', International Energy Agency, New York.

Kelemen, R.D. (2015) 'Lessons from Europe: What Americans Can Learn from European Public Policies', CQ Press, Washington, DC.

Knieps, M. (2004) 'Aufgabenträger oder Verkehrsunternehmen als Gesellschafter von Verkehrsverbünden ?', Justus-Liebig-Universität, Giessen, Germany.

Koch, M., Newmark, G. (2017) 'Legislating Transit “Coopetition”: Privatization and Planning Devolution in Germany', Transportation Research Record: Journal of the Transportation Research Board, 2543(pp. 45-51

Krause, R. (2009) The Hamburger Verkehrsverbund from 1965 until today. Hamburger Verkehrsverbund (HVV), Hamburg.

Litman, T. (2004) 'Transit price elasticities and cross-elasticities', Journal of Public Transportation, 7(2), pp. 37-58

Litman, T. (2017a) Evaluating Public Transit Benefits and Costs. Victoria Transport Policy Institute, Victoria, British Columbia.

Litman, T. (2017b) Transit Price Elasticities and Cross-Elasticities. Victoria Transport Policy Institute, British Columbia.

Matas, A. (2004) 'Demand and revenue implications of an integrated public transport policy: The case of Madrid', Transport Reviews, 24(2), pp. 195-217

Mees, P. (2010) Transport for Suburbia: Beyond the Automobile Age. Earthscan, New York City, NY.

MOP (2017) The German Mobility Panel. Karlsruhe Institute of Technology, Karlsruhe.

MVV (1990-2015) Annual Report. Munich Regional Public Transport Association (MVV), Munich, Germany.

MVV (2012) 40 Years of MVV. MVV, Munich, Germany.

MVV (2017) 'Second Main Tunnel / Stammstrecke', MVV, Munich, Germany.

Newman, P., Kenworthy, J. (1999) Sustainability and cities. Island Press, Washington D. C.

Newman, P., Kenworthy, J. (2015) The End of Automobile Dependence: How Cities are Moving Beyond Car-Based Planning. Island Press, Washington, DC.

Novy, M. (2009) 'Überblick über die Verbundlandschaft in Österreich', in VDV (ed) Verkehrsverbünde, VDV, Köln, Germany. 
O’Sullivan, P.J., Patel, T. (2005) 'Fragmentation in transport operations and the case for system integrity', Transport Policy 11, 11(pp. 215-225

Parry, I., Small, K.A. (2009) 'Should Urban Transit Subsidies Be Reduced? ', Am. Econ. Rev., 99(3), pp. 700-724

Paulley, N., Balcombe, R., Mackett, R., Titheridge, H., Preston, J., Wardman, M., Shires, J., White, P. (2006) 'The demand for public transport: The effects of fares, quality of service, income and car ownership', Transport Policy, 13(pp. 295-306

Petersen, T. (2016) 'Watching the Swiss: A network approach to rural and exurban public transport', Transport Policy, 52(3), pp. 175-185

Preston, J. (2012) Integration for Seamless Transport. International Transport Forum, Paris, France.

Pucher, J., Kurth, C. (1996) 'Verkehrsverbund: The success of regional public transport in Germany, Austria and Switzerland', Transport Policy, 2(4), pp. 279-291

Pucher, J., Lefevre, C. (1996) The urban transport crisis in Europe and North America. MacMillan Press.

Redman, L., Friman, M., Garling, T., Hartig, T. (2013) 'Quality attributes of public transport that attract car users: A research review', Transport Policy, 25(pp. 119-127

Rivasplata, C., Iseki, H., Smith, A. (2012) 'Transit Coordination in the U.S.: A Survey of Current Practice', Journal of Public Transportation, 15(1), pp. 53-73

Rollinger, W., Amtmann, G. (2012) Handbuch Öffentlicher Verkehr. Österreichische Verkehrswissenschaftliche Gesellschaft, Vienna, Austria.

Shoup, D.C. (2011) The high cost of free parking. Planners Press, American Planning Association, Chicago.

Sørensen, C.H., Longva, F. (2011) 'Increased coordination in public transport—which mechanisms are available?', Transport Policy, 18(pp. 117-125

Stead, D. (2008) 'Institutional aspects of integrating transport, environment and health policies', Transport Policy, 15(pp. 139-148

Steinbauer, G. (2015) 'Personal Interview with Director, Wiener Linien', in Buehler, R. (ed), Vienna, Austria.

Suzuki, H., Cervero, R., Iuchi, K. (2013) Transforming Cities with Transit: Transit and LandUse Integration for Sustainable Urban Development. The World Bank, Washington, DC.

Topp, H.H. (1989) 'Cooperation in transit delivery in West German metropolitan areas', Transportation, 15(4), pp. 279-295

TRB (2001) 'Making transit work: Insight from Western Europe, Canada and the United States', Transportation Research Board, National Research Council, National Academy Press, Washington DC.

UITP (2014) Organization and Major Players of short distance public transport. International Association of Public Transport, Brussels, Belgium.

UN Habitat and European Union (2016) 'State of European Cities in 2015. "Urban Transportation,” ch. 5', UN Habitat and European Union., Nairobi, Kenya and Brussels, Belgium.

van de Velde, D. (1999) 'Organisational forms and entrepreneurship in public transport, Part 1: classifying organisational forms', Transport Policy, 6(2), pp. 147-157

van de Velde, D. (2001) 'The evolution of organisational forms in European public transport', 7th Conference on Competition and Ownership in Land Passenger Transport, Molde, Norway. 
van de Velde, D. (2014) 'Market initiative regimes in public transport in Europe: Recent developments', Research in Transportation Economics 48(1), pp. 33-40

Vassilakou, M. (2015) 'Personal Interview with Vice-Mayor and Minister of Transport for the City of Vienna, 2010-today, Green Party', in Buehler, R. (ed), Vienna, Austria.

VBB (2000-2015) Annual Report. Regional Public Transport Authority for Berlin and Brandenburg (VBB), Berlin, Germany.

VDV (2001-2017) 'VDV Statistik', VDV, Cologne.

VDV (2009) Transport Alliances. German Public Transport Association, Cologne, Germany.

Vollmer, P. (2009) 'Only few understand how it works: Financing public transport in

Switzerland', Regional Schiene, 2009(7), pp. http://www.regionaleschienen.at/0_thema_200907.asp?mid=200923

Vollmer, P., Schiesser, H.K. (2009) 'The emergence and significance of fare alliances in Switzerland', in VDV (ed) Transport Alliances, VDV, Cologne.

VOR (1990-2015) Annual Report. Regional Public Transport Association for the Vienna Region (VOR), Vienna, Austria.

VRR (1990-2016) 'Annual Report', VRR, Gelsenkirchen, Germany.

VRR (2015) '35 Years VRR', VRR, Gelsenkirchen, Germany.

Vuchic, V. (1999) Transportation for livable cities. Center for Urban Policy Research (CUPR), New Brunswick, NJ.

Vuchic, V. (2005) Urban Transit: Operations, Planning, and Economics. Wiley \& Sons, Hoboken, NJ.

Webster, F.V., Bly, P.H. (1981) 'The demand for public transport. part I. The changing environment in which public transport operates', Transport Reviews, 1(4), pp. 323-351

White, P. ( 2016) Public Transport: Its Planning, Management and Operation, 6th ed. Routledge, London, UK.

Yago, G. (1984) The decline of transit : Urban transportation in German and U.S. cities, 19001970. Cambridge University Press, New York.

ZVV (2015) Public Transport in the Zurich Region. Regional Transport Association (ZVV), Zurich. 